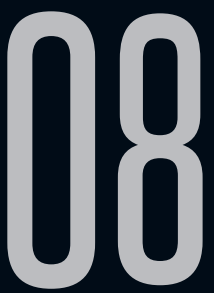

\title{
A HUMANIZAÇÃO DO MONSTRO NO SERIADO TELEVISIVO PENNY DREADFUL
}

Enéias Farias Tavares

Bruno Anselmi Matangrano

Recebido em 25 jan 2016. Enéias Farias Tavares - professor doutor em estudos Aprovadoem 07 mar 2016. literários e professor adjunto do Departamento de Letras Clássicas e Linguística da Universidade Federal de Santa Maria, atuando como coordenador substituto de programa de Pós-Graduação em Letras da mesma instituição. Concluiu mestrado em Literatura Comparada (2008) sob orientação do Prof. Dr. Lawrence Flores Pereira. Durante a escrita da dissertação, traduziu Otelo - O Mouro de Veneza, de Shakespeare, trabalho que recebeu montagem teatral sob a direção de Aline Castaman no mesmo ano. Sua tese de doutorado (2012) trata da arte poética e pictórica de William Blake. Em 2011, realizou parte de sua formação (doutorado sanduíche) na Universidade de York (Inglaterra) sob orientação do professor Michael Phillips e no Morley College of London, onde reproduziu a técnica usada pelo artista inglês para criar seus livros iluminados. Trabalha com literatura clássica, poéticas interartes e literatura e pintura do século XIX. Entre suas publicações mais significativas estão o livro Discursos do Corpo na Arte (2014) e o romance A lição de anatomia do temível Dr. Louison (2014), primeiro volume da série de ficção retrofuturista Brasiliana Steampunk, romance ganhador do Prêmio Fantasy, da Casa da Palavra/ LeYa. Lattes: http://lattes.cnpq.br/1655076745935830 Contato: eneiastavares@gmail.com 
Bruno Anselmi Matangrano - mestre e doutorando em Literatura Portuguesa pela USP e, atualmente, realiza estágio de pesquisa como investigador-visitante na Universidade de Lisboa, sob financiamento do Conselho Nacional de Desenvolvimento Científico e Tecnológico (CNPq). É membro do Grupo de Pesquisa Poéticas e Éticas da Modernidade (POEM) e do Laboratório de Estudos de Poéticas e Ética na Modernidade (LEPEM). Dedica seus estudos às literaturas simbolista $\mathrm{e}$ fantástica, escritas em português e em francês. Desde 2012, é também coeditor das revistas acadêmicas: Desassossego, do programa de pós-graduação em Literatura Portuguesa da USP, e Non Plus, do programa de Estudos Linguísticos, Literários e Tradutológicos em Francês. Além disso, possui artigos, traduções e contos publicados, dentre os quais se destacam: o artigo "Cisne Isolado, Sujeito Deslocado - Mallarmé em diálogo com Apolo, Baudelaire, Andersen e Eduardo Guimaraens" (Revista Aletria, UFMG, 2015), a tradução e estudo de $O$ Pequeno Príncipe, de Saint-Exupéry (Giz Editorial, 2015), e o livro Contos para uma Noite Fria (Llyr Editorial, 2014). Lattes: http://lattes.cnpq.br/2139289828609663 Contato: bamatangrano@yahoo.com.br

Resumo: Neste artigo, analisaremos a série televisiva Penny Dreadful, produzida pelo canal norte-americano Showtime entre 2014 e 2015. Nossa leitura demonstrará como o roteirista John Logan revisita monstros clássicos da literatura vitoriana para propor relevantes discussões sociais. Para tanto, escolhemos dois eixos interpretativos, centrados em pares de personagens e suas interações, abordando os temas da identidade e alteridade e as dúbias definições de gênero e afetividade, recorrendo a autores como David Roas, Julio Jeha e José Gil e ao livro de Sharon Gosling, que apresenta entrevistas com o elenco e criadores. 
Palavras-chave: Humanização do Monstro; Monstro Clássico; Monstro Social; Identidade; Alteridade; Horror em Séries Televisivas.

Abstract: This paper aims to analyze the television series Penny Dreadful, produced by the NorthAmerican broadcast company Showtime between 2014 and 2015. Our reading will discuss how screenwriter John Logan revisits traditional monsters from Victorian literature in order to present relevant social topics. Thus we chose two interpretive lines, based on two pairs of characters and their interactions, discussing themes such as identity and alterity, and the dubious definitions of gender and affection. We employed works by authors such as David Roas, Julio Jeha and José Gil, and Sharon Gosling's book, featuring interviews with the cast and creators of the show.

Keywords: Humanization of the Monster; Classic Monster; Social Monster; Identity; Alterity; Horror in Television Series.

\section{INTRODUÇÃO}

O horror psicológico enquanto categoria narrativa figura muitas vezes como alegoria para medos, ansiedades, temores e assimetrias sociais entre uma determinada parcela da população masculina, letrada, dita civilizada - e outra comumente minoritária, oprimida, excluída da sociedade e dos seus elaborados - e muitas vezes violentos - regramentos sociais. Neste contexto, os monstros surgem na forma de párias, construtos ficcionais utilizados não apenas para produzir medo, mas também como vias de reflexão sobre problemas sociais. 
Neste âmbito, nasce Penny Dreadful, um seriado estadunidense produzido pelo canal Showtime, cuja primeira temporada foi exibida em 2014 e a segunda no ano seguinte. Criada e roteirizada por John Logan - indicado várias vezes ao Oscar de melhor roteiro - e produzida pelo premiado Sam Mendes, o título alude às publicações baratas produzidas em Londres no final do século XIX, que traziam versões apelativas de notícias policiais e produções fictícias, envolvendo crimes e intrigas.

Dentro de uma perspectiva dos estudos do insólito como categoria narrativa, a série se apresenta como produção híbrida, sendo a um só tempo obra de horror fantástico, na esteira dos clássicos desta vertente, como também obra de ficção alternativa, ou ucronia ficcional, variante da história alternativa que prevê "um incidente sobre o eixo histórico, introduzindo uma hipótese plausível pela qual faça derivar o curso da História" (FONDANÈCHE, 2006, p.3, tradução nossa); ou seja, uma história que prevê, a partir de enredos já existentes - reais ou fictícios - novas tramas, conforme fizeram antes autores como Alan Moore na série de novelas gráficas The League of Extraordinary Gentleman (1999), ou Kim Newman no romance Anno Dracula (1992).

Em Penny Dreadful, o criador John Logan recria num mesmo universo personagens literários preexistentes em obras de autores diversos, como Drácula, Mina Harker e Abraham Van Helsing, criados por Bram Stoker (1847-1912) em 1897, interagindo com Victor Frankenstein e sua Criatura, concebidos por Mary Shelley (1797-1851) em 1818, numa Londres que testemunha os passeios noturnos e as experimentações estéticas - quando não criminosas - de Dorian Gray, herói criado em 1890 por Oscar Wilde (1854-1900). A este elenco 
literário, contrapõem-se outros monstros inéditos. Há um lobisomem de origem norte-americana que foge de um passado obscuro chamado Ethan Chandler, contratado por Sir Malcolm Murray, um explorador inglês que busca pela filha desaparecida e é o responsável pela união dos diferentes monstros - ou heróis, a depender de como os interpretamos. No centro desses personagens estão duas figuras femininas de relevo. A primeira é Vanessa Ives, dama cujo passado também está imerso em sombras e demônios, que tem uma dívida de sangue com Murray. A segunda é a prostituta tuberculosa Brona Croft, que tanto será contratada por Gray quanto será o interesse afetivo de Chandler, até morrer às mãos de Frankenstein e ser ressuscitada como parceira para sua Criatura.

Por outro lado, para além do viés ucrônico, do ponto de vista da ambientação e do efeito no espectador, Penny Dreadful é uma obra de horror tradicional - apesar de produzida e escrita no século XXI -, seguindo os parâmetros dos romances oitocentistas revisitados; ou seja, enquadra-se na categoria do "horror sobrenatural" lovecraftiano, definido por sua atmosfera "inexplicável e empolgante de pavor de forças externas desconhecidas" e por suscitar ao leitor/telespectador um medo intrínseco ante o desconhecido (LOVECRAFT, 2007, p.17-18), de forma a lhe causar comoção e catarse. No mesmo caminho, enquadra-se no fantástico por trazer "o conflito entre o real e o impossível", como previsto por David Roas (2008, p.103-104).

O horror tradicional de Penny Dreadful, no entanto, não deixa de trazer inovações contemporâneas, segundo explica Patricia Llobera em seu artigo sobre os monstros da série American Horror Story, no qual considera Penny Dreadful um expoente 
do new horror. Segundo ela, esta reformulação da categoria lovecraftiana surge da revisitação dos romances góticos, na qual, para além das características clássicas repensadas a partir de um conceito de bricolagem (também comum na ucronia), soma-se a superexposição da crueza e da violência. A autora considera que diversas séries contemporâneas, como True Blood (2008-2014), The Walking Dead (2010) e The Strain (2014) pertencem a esta recente categoria, pois, para ela:

Todas ellas enfatizarán, a través de argumentos y estéticas muy diferenciadas, las acciones violentas como metáfora de la deshumanización de la sociedad, el retorno de lo gótico y, de manera especial, la caracterización de los monstruos como seres muy cercanos a los humanos con los que pueden llegar a confundirse (Platts, 2014). O, si se prefiere, construirán una concepción postmoderna del horror. (2015, p.71)

Ou seja, no new horror, para além da crueza das imagens, destaca-se o apagamento de fronteiras entre pessoas e monstros, à medida que estes são humanizados e a sociedade é desumanizada, em complemento ao já previsto por Lovecraft e Roas.

Tendo em vista os limites e conceitos destas categorias narrativas, o presente artigo pretende analisar o processo de humanização das variadas formas de apresentação de monstros, recriados por Logan, numa ambientação oitocentista, mas vistos a partir de paradigmas contemporâneos. Para tanto, a análise se dará por meio de dois pares de personagens: Vanessa Ives e a Criatura de Frankenstein (também identificada como Caliban e John Clare) e Dorian Gray e Angelique, respectivamente: um Monstro Sobrenatural (bruxa), 
um Monstro Biológico (criatura feita em laboratório), um Monstro Moral (homem imortal) e um Monstro Social (mulher transgênera), ou seja, dois monstros canônicos e dois monstros modernos, monstros de fato (aparência) e monstros de direito (essência), monstros literais e monstros metafóricos etc. - passíveis de serem esquematizados em outras dicotomias. Primeiramente, contudo, convém algumas palavras sobre o conceito de "monstro" e a forma como a série os (re)pensa e os (re)cria, no âmbito de uma obra de horror sobrenatural e filiada à ucronia ficcional.

\section{DA HUMANIZAÇÃO DE MONSTROS EM PENNY DREADFUL}

Em sua origem etimológica, a palavra "monstro" designa uma advertência divina, um presságio dos deuses, como nos explica o filósofo José Gil em seu tratado Monstros, a partir dos estudos do linguista Emile Benveniste (2006, p.73). Nesta perspectiva, o nascimento de uma criança com alguma deficiência física designaria uma vontade ou descontentamento divino. Ao longo dos séculos, o termo passou a designar o esteticamente horrível e, ao mesmo tempo, incompreensível e anormal. Com o tempo, passou a abarcar o moralmente feio, extrapolando, portanto, o campo físico. Não raro, a monstruosidade nascia de um excesso ou de uma ausência, e quase sempre a designação era acompanhada pela ignorância e pelo medo. Assim, aos poucos, o diferente tornou-se monstruoso. Por outro lado, Roas afirma:

El monstruo encarna la transgresión, el desorden. Su existencia subvierte los límites que determinan lo que resulta aceptable desde un punto de vista físico, biológico e incluso moral. Por ello, el monstruo siempre implica la existencia de una 
norma: es evidente que lo anormal sólo existe en relación a lo que se ha constituido o instaurado como normal. (2014, p.108)

Logo, o conceito de "monstro" está originária e obrigatoriamente ligado à ideia de "transgressão". Como Roas diz mais adiante no mesmo texto, o monstro é o "Outro", definido pelo que está além do normal (2014, p.110), logo se torna uma questão de identidade e alteridade.

Mas por que o homem imaginaria tais transgressões? Segundo Gil, o monstro apareceu como conceito pela necessidade de se nomear e explicar o desconhecido, mais do que isso, é a partir do paradigma do "monstruoso" que se começa a pensar no "humano" (2006, p.53-54). Já para Julio Jeha, os “Monstros corporificam tudo que é perigoso e horrível na experiência humana. Eles nos ajudam a entender e organizar o caos da natureza e o nosso próprio" (2007, p.7), além disso, o termo se atualiza, e

modernamente, a Criatura de Frankenstein inaugura uma linhagem de monstros que falam do nosso mal-estar perante o desenvolvimento da ciência e o progresso tecnológico, assim como diante de guerras e genocídios (2007, p.7).

Além disso,

os monstros desempenham, reconhecidamente, um papel político como mantenedor de regras sociais. Grupos sociais precisam de fronteiras para manter seus membros unidos dentro delas e proteger-se contra os inimigos fora delas (2007, p.20).

Ou seja, definindo-se quem pertence ou não a determinado grupo, surge a ideia do estrangeiro como monstro, já sinônimo de outsider, 
ou pária social. "O monstro é um estratagema para rotular tudo que infringe esses limites culturais" (2007, p.20).

No universo das artes, o "monstro" comumente se traduziu como metáfora; no entanto, no século $X X$, esse paradigma começou a sofrer transformações, permitindo o que a crítica chamou de "humanização do monstro" (ROAS, 2012 e 2014). Roas identifica esta mudança em dois momentos principais: a publicação de Entrevista com o Vampiro, de Anne Rice (1976) e o filme Drácula de Bram Stoker, de Francis Ford Coppola (1992). Porém, os vampiros dessas obras ainda se mantêm como monstros - humanizados, sim, mas ainda monstruosos -, capazes de praticar o mal e suscitar o medo, ao contrário de produções mais contemporâneas que colocam o monstro numa condição de herói ou príncipe, o que Roas chama de "monstro domesticado" em oposição ao "monstro predador" (o clássico) e ao "monstro humanizado" (o vampiro Lestat de Rice, por exemplo) (2014, p.111).

Sem negar o percurso traçado pelo teórico espanhol, importa dizer que o processo de transformação da figura do monstro não é de todo recente, posto que muito gradual. Gil comenta que os monstros sempre exerceram fascínio sobre os homens, desde a Antiguidade clássica até os dias de hoje, dos seres mitológicos aos psicopatas atuais; contudo, a natureza do monstro permanece em constante mudança: na Renascença "o interesse pelos nascimentos monstruosos impõe-se totalmente, apagando as raças fabulosas" (nas quais não mais se acredita), já que o homem muda, "assim como a sua representação e o seu modo de viver o espaço e o tempo" (2006, p.19). Desta forma, parece natural que a raça fabulosa da Antiguidade Clássica evolua no imaginário humano para o interesse 
pelos monstros teratológicos (como nos Cirques des Freaks), e em seguida para os monstros artificiais: biológicos, como a própria Criatura de Frankenstein; alquímicos, como golens e homúnculos; ou ainda, mecânicos, como autômatos e robôs. Por fim, o monstro parece ter evoluído para o próprio ser humano de caráter desviado, vide psicopatas e serial killers. A atualização de monstros se torna natural, portanto, e demonstra que o homem contemporâneo se questiona acerca de sua própria humanidade (2006, p.11).

Penny Dreadful se insere nessa tradição, explorando a um só tempo monstros clássicos predadores, como os vampiros e bruxas necromantes, sem qualquer profundidade e maniqueístas em sua essência, e monstros humanizados, como os de Rice e Coppola, criaturas profundas, capazes de sentir e se expressar, sem perderem o caráter de anti-herói ambíguo e mantendo-se como outsiders, posto que não sejam incorporados à sociedade retratada. São estes últimos o tema da presente análise.

Desde o início de sua produção, nos idos de 2009, Penny Dreadful fora previsto por John Logan como um programa televisivo que poderia tanto revisitar monstros clássicos num programa de grande apelo comercial, como também abordar assuntos e temas incomuns a produções de horror ou terror. Para tal empreitada, encontrou no diretor e produtor inglês Sam Mendes um parceiro mais do que adequado. Para Mendes, o horror sempre foi um canal válido para se refletir sobre temas psicológicos complexos. Penny Dreadful resulta, segundo ele, numa tentativa de "finally take Gothic horror seriously again in a way that was understanding of the fact that Gothic horror was created as a metaphor for the human condition" (Apud GOSLING, 
2015, p.10). John Logan, refletindo sobre sua concepção inicial para a série, afirma:

The ultimate challenge and goal of Penny Dreadful is really simple. It's to say, "We are all monsters." Within all of us we have secrets, we have demons, we feel alienated from the world around us. For the unbelievable Victorian locations and costumes, for the complexity of the plot, for the intricate nature of the characters and the relationships, it's a story about love. It's a story about human beings searching to be happy. Whether those human beings are actual human beings, reanimated corpses, vampires, or any other demon you can name, they're all searching for the same think, which is someone to look back at them with compassion. (Apud GOSLING, 2015, p.15)

O elenco também concorda com essa interpretação, sendo que muitos dos atores aceitaram participar de Penny Dreadful especialmente pela dimensão psicológica que seus criadores queriam explorar. Para Josh Hartnett, por exemplo, que interpreta o pistoleiro - e lobisomem - Ethan Chandler, "all the characters in this show feel alienated in some way. They're alienated by the secrets they keep and are in want of relationships that will help take away that feeling of alienation, help them be understood" (Apud GOSLING, 2015, p.19).

Para Sharon Gosling, Logan criou uma série que toca em questões muito profundas, não apenas relacionadas ao medo e ao horror, como também às próprias relações humanas e suas pontes de afeto. Segundo a autora:

Penny Dreadful is, in many ways, a story about difference and the struggles entailed in making a place for oneself in the world as an outsider. 
Vanessa's demons, Brona's slow death, Ethan's secret self, the Creature's scars - all of these denote an otherness of frank extremes. (2015, p.96)

Em meio a esta galeria de outsiders atormentados, destacamos John Clare, a primeira Criatura de Frankenstein revisitada, que já na obra de Mary Shelley era o embrião do que hoje se chama de monstro humanizado; a bruxa-que-anda-de-dia Vanessa Ives, que, apesar de atormentada por seus demônios internos, combate-os com sua fé na crença cristã e em seus ideais; Dorian Gray, o imortal enfadado, cuja moralidade se esvai com o passar do tempo e a ausência de medos naturais; por fim, temos a transexual Angelique, monstrificada pela incompreensão da sociedade de seu tempo, ainda incapaz de entender que a sexualidade humana não é passível de ser resumida em um simples binômio.

Neste aspecto, o seriado televisivo Penny Dreadful fomenta a investigação sobre o "monstro literário" em oposição ao "monstro social", fornecendo aos intérpretes um campo fértil de representações caracterológicas e atmosféricas, quando não situacionais, nas quais temas como exclusão social, caridade, solidão e gênero podem ser estudados. Dito isto, passemos a discutir essas quatro formas distintas de monstruosidade em detalhes a partir de duas dicotomias: o monstro sobrenatural e o monstro biológico, em um primeiro momento. Em seguida, o monstro moral e o monstro social.

\section{JOHN CLARE E VANESSA IVES: POESIA, ALTERIDADE E IDENTIDADE}

Para além do horror e da ação, Penny Dreadful se constrói, sobretudo, a partir de bons diálogos, perpassados de questionamentos 
ontológicos, metafísicos e existencialistas. Dentre os pares dialógicos presentes na trama, talvez um dos mais interessantes seja Vanessa Ives e John Clare, que encarnam dois tipos de monstros tornados clássicos: a bruxa e a criatura criada artificialmente.

Apesar de ambos serem atormentados pelos fantasmas de seus erros e de sua condição, não poderiam ser mais distintos. A Criatura de Victor Frankenstein, autointitulada John Clare, sofre por sua feiura e deformidade, motivo pelo qual se tornou um pária social. Renegado por seu criador, vê-se - na primeira temporada - abandonado em um laboratório semidestruído, onde precisa aprender o mundo e sobre o mundo de maneira autodidata. Quando, por fim, sai de seu microuniverso, é hostilizado, agredido e marginalizado até encontrar um homem que se lhe compadece. John Clare, portanto, é pobre, feio, desajustado e descrente, como monstro biológico que é, o oposto da personagem original de John Logan, Vanessa Ives, uma moça católica da alta sociedade londrina, de beleza estonteante e modos delicados. Miss Ives, no entanto, é médium e cresce cercada pelo sobrenatural. Dizem que foi marcada pelo diabo; é a sua volta que os acontecimentos principais da série se desenrolam. Ela foi o motivo da ruína de sua amiga Mina Murray - filha de seu amigo e benfeitor Sir Malcolm Murray -, atraindo os vampiros que assolam Londres na primeira temporada da série; enquanto na segunda, passa a ser perseguida por um grupo de necromantes. Vanessa, portanto, não é uma tímida dama oitocentista, como comenta seu criador, John Logan:

I decided to write about a female protagonist, because in 1891 London, women were quite literally corseted and constrained. The societal, 
social, sexual conventions of the day kept women bound up. I thought creating a woman who had to live in that society and yet within her had these monstrous yearnings, or these yearnings for liberation, would make a very compelling central character. So I created Vanessa Ives, who to me most perfectly personifies what it is to be a 'monster'. Meaning, on one hand, she is tormented, she is cursed with something that tears her to pieces inside, but it is that very thing that also makes her strong, powerful and liberated in a time when women couldn't be. She most perfectly embodies both sides of that monstrous balancing act. (Apud GOSLING, 2015, p.122)

Miss Ives é, por conseguinte, não apenas um Monstro Sobrenatural, devido a seus poderes mediúnicos, como igualmente um monstro social, uma vez que encarna a figura da mulher moderna, decidida e independente, movida por suas próprias ideias, vontades e impulsos, em movimento contrário ao predito pelo patriarcado opressor e conservador; caminho semelhante ao traçado por Angelique e Lily, duas outras fortes personagens femininas. Neste sentido, não se distanciam de John Clare, que, apesar de pertencente ao sexo opressor, torna-se oprimido devido à feiura e pobreza que não Ihe permitem (usu)fruir dos privilégios de sua condição. Ou seja, apesar de tamanhas diferenças dicotômicas, o Monstro Biológico, masculino, feio, ateu e pobre, encontra na figura desta Bruxa, católica e rica, uma cara amiga, pois ambos conseguem se entender - e se reconhecer - empaticamente, através da caridade e da poesia.

O primeiro encontro dos dois opostos tornados amigos se dá após os acontecimentos do primeiro episódio da segunda 
temporada. Depois de deixar Frankenstein com sua noiva recém (re)criada e de ter sido despedido do teatro onde Mr. Brand (seu primeiro benfeitor) o empregara, John Clare recomeça sua jornada à procura de trabalho pelas ruas de Londres - busca infrutífera não apenas pelos cartazes que recusam novos empregados, como também por sua própria inaptidão física e/ou profissional. Que trabalho um homem deformado e sem qualquer formação tradicional anterior poderia obter? A câmera superior em plongé apresenta não apenas a visão do homem solitário vagando pelas ruas populosas de uma metrópole igualmente inclusiva e excludente, como também os pares sociais deste monstro: infantes que mendigam seu sustento.

$\mathrm{Na}$ literatura inglesa, a figura de infantes abandonados é um tropo comum, vide os limpadores de chaminé e as crianças desabrigadas das Canções, de William Blake (1757-1827), e os infantes explorados dos romances de Charles Dickens (18121870). Confrontar John Clare a essas crianças famintas e desoladas aproxima o monstro de um problema social não apenas comum no período, mas completamente atual. Nesse sentido, poucas cenas de Penny Dreadful equacionam visualmente a figura do monstro com a do pária social, não apenas em sua invisibilidade cultural, como também em sua vulnerabilidade física, seja pela fome, seja pela exclusão profissional.

Essa abordagem também está presente no modo como os diretores e cenógrafos da série apresentam a capital inglesa. Segundo Sharon Gosling, há um cuidado com o cenário na construção, da série a fim de destacar não apenas a idealizada Londres vitoriana, mas também os subterrâneos menos 
aprazíveis ao imaginário que permeia o século XIX inglês. Segundo a autora:

The intention of Penny Dreadful was always to show Victorian London as it really was during this period. Some of this would involve images the audience would already know about, the carriages, the clothes, the architecture. Filtering between these, however, would be uncommon, forgotten delights - and monstrosities. (2015, p.102)

No caso do monstro criado por Victor Frankenstein, John Logan retoma na segunda temporada o percurso efetuado na primeira. Se antes a Criatura havia conseguido trabalho e abrigo no Grand Guignol inglês, teatro de variedade conhecido pelo valor irrisório do ingresso e pela qualidade questionável das peças apresentadas, nesta, John Clare estaca diante do Chambers of Grotesque and Gore, único lugar que expõe um cartaz de "Precisamos de Trabalhadores". O personagem sorri da ironia e adentra a casa de horrores que recria em cera cenas de violência e monstruosidade. No decorrer dos episódios, descobriremos ser dupla a exploração do monstro, uma vez que o gerente da casa deseja aprisionar Clare para expô-lo como entretenimento, o que levanta a frequente questão: quem é o homem e quem é o monstro?

Por outro lado, o percurso de Vanessa Ives envolve seus conflitos internos, uma vez que ainda não superara os acontecimentos traumáticos da primeira temporada, na qual é possuída, exorcizada, acamada e tratada em uma clínica psiquiátrica. Ao fim, seu tormento se encerra com a morte de sua amiga Mina e muitos questionamentos acerca de sua fé. Tudo isso se intensifica, quando, no primeiro episódio da segunda 
temporada, Vanessa é atacada por bruxas - não daywalkers como ela, mas nightcomers, isto é, necromantes.

Quando esses dois personagens se encontram, no segundo episódio da segunda temporada, dirigido por James Hawes, estão fugindo de seus respectivos conflitos. Para tanto, recorrem às galerias subterrâneas, onde funciona a clínica de tratamento da cólera. Mr. Clare se recolhera a tal lugar para buscar alimento e descanso, enquanto Vanessa fora procurar, em suas palavras, "um pouco de paz", incentivada por Sir Malcolm, que percebera em sua protegida, amiga e filha de consideração, uma inquietação angustiante e incessante.

Se, na primeira temporada, foram os subterrâneos dominados por vampiros ou os calabouços dos viciados em ópio os responsáveis por contrastar o terror tradicional com o social, agora são as catacumbas das bruxas que são emparelhadas aos redutos de doentes pobres atendidos por freiras e localizados abaixo da superfície da cidade, como algo a ser escondido ou ignorado.

Mr. Clare e Miss Ives se encontram apenas três vezes ao longo das duas temporadas - as três neste mesmo local -, apesar de todo o tempo estarem próximos devido às ligações em comum. Tais encontros se dão nos episódios dois, cinco e dez - respectivamente, no começo, no meio, e no fim - da segunda temporada, e servem como um momento de alento em meio ao horror, seja para as personagens, seja para o espectador.

O primeiro diálogo se inicia com apresentações formais, mas logo envereda por outros caminhos, tocando questões delicadas, como literatura e religião, quando Vanessa comenta que as freiras - 
coordenadoras da clínica - a deixam nervosa. Então, pergunta se Mr. Clare tem religião, e ele, sem lhe responder ainda, coloca outra questão:

\section{CLARE: Are you offering it?}

IVES: Do you require it?

CLARE: I never have.

IVES: Then I shan't offer. And I would be a poor advocate. The Almighty and I have a challenging past. Not sure we're speaking these days.

Apesar de pouco ou nada saberem um do outro, nasce uma cumplicidade entre os dois. Os diálogos não são longos, mas profundos, pois tocam dimensões delicadas da espiritualidade e efemeridade humana. A mera transcrição do conteúdo os esvazia de sentido, uma vez que são permeados por hesitações, sorrisos e olhares consternados. Naquele submundo, não há inimigos; não há bruxas, demônios ou monstros, apenas duas pessoas tentando entender a si mesmas e ao mundo.

Vanessa expõe, então, sua relação - agora ambígua - com a Igreja Católica, sem precisar, no entanto, explicitá-la. O problema é mencionado, sugerindo os debates íntimos que a corroem, ao que John Clare responde, de modo humilde - talvez profano - que, apesar de ter lido a Bíblia "quando jovem", esta se tornou "anêmica", ao descobrir a poesia de William Wordsworth (1770-1850). A partir de então, os diálogos dos dois serão permeados por poesia, tema aliás constituinte da identidade de John Clare, que aprendeu a ler, antes mesmo de falar, no laboratório de Victor Frankenstein.

Autodidata, alfabetiza-se pela poesia romântica, enquanto vê o mundo pelo vidro de um único cômodo. Absorve, assim, dessas duas "janelas" tudo o que pode, criando sua concepção melancólica 
e aterrorizante de mundo. Sua formação se dá solitária, pela poesia e pela visão. À medida que se desenvolve, a literatura volta a encontrá-lo, sobretudo no teatro shakespeariano de Vincent Brand, que o nomeia Caliban. Vale lembrar a passagem da primeira temporada, quando, em um diálogo com Victor, que questiona o que sua criação quer de si, o então Caliban responde: "In this life, there are hungers that compel us. Food, shelter, warmth, even poetry". Ou seja, mais que um gosto ou um capricho, para ele a poesia é uma necessidade, tão vital quanto comida ou abrigo.

Da mesma forma que Caliban absorve a beleza da poesia para sua essência, Clare incorpora parte da maldade intrínseca à raça humana, que até então lhe era estranha e não natural, de modo a cumprir com os preceitos rousseaunianos, já evidentes em Mary Shelley (2013). Felizmente, para Caliban, ao contrário da Criatura de Shelley, o mal não o corrompe totalmente, nem o controla, mas passa sim a coexistir em seu íntimo, sendo despertado pelos vícios humanos, como os vistos em Victor e na família Putney, responsável pelo fracassado Cirque du Freak, onde queria aprisioná-lo.

Dando continuidade ao diálogo, Miss Ives comenta:

IVES: Mr. Wordsworth has a lot to answer for, then. CLARE: Is it not this, Miss Ives, the glory of life surmounts the fear of death. Good Christians fear hellfire, so to avoid it, they are kind to their fellow man. Good pagans do not have this fear, so they can be who they are, good or ill, as their nature dictates. We have no fear of God, so we are accountable to no one but each other.

IVES: That's a profound responsibility.

CLARE: And why you do this, no doubt. Helping those in need. 
IVES: I came here for selfish reasons. Do you truly not believe in heaven?

CLARE: I believe in this world and those creatures that fill it. That's always been enough for me. Look around you. Sacred mysteries at every turn.

IVES: But no exaltation in life beyond this?

CLARE: To see a world in a grain of sand / And a heaven in a wild flower / Hold infinity in the palm of your hand / And eternity in an hour.

IVES: With respect to Blake, I see no wild flowers here, only pain and suffering.

CLARE: Then you need to look closer.

A partir de Wordsworth, a Criatura discorre sobre uma perspectiva otimista da vida, na qual não há céu nem inferno, apenas a beleza, contida em cada pequena coisa. Curiosamente, a despeito de sua própria fé oscilante, Miss Ives não se ofende; antes, tenta reproduzir o exercício de enxergar o belo nos detalhes. As remissões a William Blake e a Wordsworth apontam para soluções - senão sociais, então imaginativas - para as mesmas inquietações que perpassam os pensamentos de Ives e as vivências de Clare. Nesse jogo de referências compartilhadas, nasce uma compreensão e, a partir dali, tornam-se amigos. Antes de sair, Vanessa se volta para Mr. Clare e comenta: "Você tem belos olhos", percebendo, em sua delicadeza, aquilo que ele precisava ouvir.

Tal diálogo contrasta - e muito - com a outra faceta de John Clare, o assassino de Proteus - a segunda cria de Victor - e de Dr. Van Helsing, chegando mesmo a clamar o desejo de sobrepujar a raça humana, destruindo todos ao redor de seu criador. No entanto, isto diz tanto a respeito de John quanto de Victor, que devido a seus atos hediondos, seu egoísmo egocentrado e sua 
incapacidade de exercitar empatia pelo que não entende, desperta o pior em sua sensível criação, cuja redenção é a poesia. A questão é de novo a mesma: quem é o homem e quem é o monstro? Isso evoca a ideia de que os "homens precisam de monstros para se tornarem humanos" (GIL, 2006, p.83); ou seja, tanto Victor quanto John tornam-se mais monstruosos e mais humanos - embora de forma diferente - quando cotejados. Paralelamente, Vanessa, em sua busca por paz anterior, vê na caridade - presente não apenas na entrega de sopa aos pobres, mas também por se permitir ver a beleza dos olhos de um monstro - um caminho.

Assim, John e Vanessa trazem em si demônios; ele de sua criação profana, ela de sua ligação com a bruxaria e passado de (suposta) loucura. Nas câmaras dos doentes, todavia, encontramse em espaço neutro, onde não vão para serem julgados e sim para acolherem e serem acolhidos. Despidos de qualquer necessidade de explicações, podem se ver como realmente são, sem papéis sociais e pecados anteriores. Assim, nasce a admiração e o entendimento mútuo. Não é estranho, portanto, que os encontros nunca se passem na cidade. Os três encontros em que conversam só acontecem no subterrâneo - neste "não lugar" -, onde as outras relações são deixadas de lado, para que conversas atemporais sobre caridade e poesia possam alentar seus corações atormentados.

Dando prosseguimento, no quinto episódio da segunda temporada, o diálogo se intensifica. Os já amigos se cumprimentam e então, jocosamente, Miss Ives pergunta se John Clare sabe que tem o mesmo nome "de um poeta morto". É interessante atentar para o fato de em ambos os encontros ser Vanessa quem inicia a conversa, com seus modos gentis, mas ousados, enquanto Mr. Clare, 
a princípio tímido, só aos poucos parece mais à vontade - outra vez, quebrando possíveis estereótipos. John Clare então Ihe pergunta se gosta de poesia - uma pergunta denunciadora de sua falta de traquejo social, visto que no diálogo anterior Vanessa reconhecera os versos de Blake. Ao que ela responde: "All sad people like poetry. Happy people like songs". Ambos sorriem e de novo compartilham um entendimento mútuo, reconhecendo a melancólica verdade daquelas palavras. Mr. Clare comenta, em seguida, que sempre se sentiu atraído pelo poeta cujo nome herdara, já que este, por sua baixa estatura, também era considerado um freak, uma aberração, tendo uma "singular affinity with the outcasts and the unloved... the ugly animals... the broken things".

Vale dizer que para entender a dimensão psicológica da Criatura de Frankenstein recriada por John Logan, é possível recorrer às duas personalidades cujos nomes assume: Caliban (na primeira temporada) e John Clare (na segunda). O primeiro é uma sugestão de Vincent Brand, o diretor do teatro Grand Gignol que consegue, por meio de sua empatia e caridade, fazer o exercício de alteridade e se colocar no lugar do pobre homem deformado. O nome remete ao criado disforme de Próspero, na última peça de Shakespeare, A Tempestade - ou seja, este primeiro nome reforça e retoma sua monstruosidade aparente.

O segundo, por outro lado, é escolhido pela própria Criatura. Essa diferença entre ser nomeado e nomear-se é significativa (seu próprio criador jamais o nomeou), assim como é sugestiva a escolha de um poeta inglês romântico, cuja vida foi bastante atribulada, pautada por um sentimento intrínseco de solidão reclusa, sensibilidade e empatia. Ao fazer esta opção, o novo Mr. Clare 
evidencia sua importância intelectual, em detrimento (e apesar) de sua figura monstruosa. Ou seja, se o primeiro nome evidenciava sua alteridade, e, por consequência, sua condição de pária, monstro e outsider, o novo nome é a afirmação de sua identidade, enquanto ser humano sensível e inteligente. É a vitória da essência sobre a aparência, em um esforço de imposição contínua da própria vontade de se fazer ouvir.

No diálogo final, passado nos últimos minutos do capítulo que encerra a temporada, há ligeira diferença de cenário e atmosfera. Como sempre, a dupla se encontra no subterrâneo; desta vez, todavia, não há freiras nem doentes. John Clare está só - um espelho de como se sente - quando Vanessa o encontra. Ambos estão devastados. Ele por ter acabado de assassinar o casal de antigos patrões que tentara escravizá-lo. Miss Ives, por sua vez, acabara de enfrentar as bruxas-necromantes e perdera um amigo. Desta vez, diferente dos encontros anteriores, é Mr. Clare quem coloca uma questão:

CLARE: Miss Ives. Why are you here?

IVES: I needed a friend.

CLARE: Won't you sit?

IVES: Are you leaving?

CLARE: Yes.

IVES: For long?

CLARE: Forever.

IVES: Where will you go?

CLARE: Where I belong. Away from mankind. This dream I had this this long dream of kinship with those unlike me it is gone.

IVES: Yes. 
CLARE: When you have seen that of which you are capable when you have stood in blood long enough what is there left but to wade to a desolate shore, away from all others?

IVES: Yes.

A forma como Vanessa vai concordando com as falas de Clare contrasta com seus modos habituais e transparece a dor imensa a corroê-la. Seus olhos estão marejados, seu rosto consternado, assim como o de Clare, que pela primeira vez - em seus diálogos com Vanessa - se coloca na posição de "não humano", motivo pelo qual quer se afastar da raça dos homens.

É interessante notar que, em sua própria angústia, Miss Ives não tenta dissuadi-lo, afinal, o sentimento de despertencimento é mútuo. Ambos são outsiders - de maneiras diferentes -, mas ainda assim, monstros. Na fala seguinte, a Criatura lhe pergunta onde seria seu refúgio, ao que Vanessa responde, demonstrando todo o seu desespero, de já não pertencer a lugar algum, pois perdeu sua alma:

IVES: There is no place far enough. I've lost the immortal part of myself, you see. No. I've thrown it away.

CLARE: No matter how far you have walked from God he is still waiting ahead.

IVES: You don't believe in God.

CLARE: But you do.

IVES: That dream is gone.

CLARE: Come with me? Our desolate shore?

IVES: Mr. Clare there is around me a shroud that brings only pain. I won't allow you to suffer. Not you. I think you are the most human man I have ever known. 
Nas falas finais, após Mr. Clare convidá-la para compartilhar de seu exílio, Vanessa responde que não Ihe quer fazer mal, e diz isso acariciando suavemente o rosto disforme do amigo. Em seguida, exalta toda a humanidade latente sob as cicatrizes e então o beija nos lábios, um beijo terno. Ela o deixa e ele, completamente sozinho nas catacumbas dos afligidos pela cólera, chora.

Na cena seguinte, John Clare é mostrado em um barco no Ártico, tal como acontece com Criatura e criador no livro de Mary Shelley, enquanto Vanessa aparece apagando as luzes e fechando a casa de Sir Malcolm. O sentimento de solidão - tão presente no último diálogo dos dois - permanece até o fim do episódio, que mostra o quão abandonada cada uma das personagens está, perdidas em si mesmas, humilhadas pelo resto da humanidade, incompreendidas e taxadas de monstros. Em sua última fala, para si mesma, Vanessa diz: "So we walk alone", ecoando a frase final da carta que Ihe deixa um Ethan Chandler enjaulado e expatriado. No ato final, ela queima a cruz para a qual rezou durante as duas temporadas, como a sentenciar que de fato estará completa e inequivocamente sozinha.

\section{DORIAN GRAY E ANGELIQUE: NOS ESPAÇOS LIMÍTROFES DO MORAL E DO SOCIAL}

O Dorian Gray de Penny Dreadful é um personagem que passeia por zonas limítrofes, sejam elas sociais, culturais ou mesmo sexuais, sendo uma das mais eficazes reinterpretações de John Logan, ao lado da excelente atuação de Reeve Carney, que imprime em sua performance uma ingenuidade juvenil ao lado de um pendor destrutivo e perverso. Essa rica faceta psicológica 
intensificada pelo verniz de eterna jovialidade figura no texto de Wilde, no qual Gray não apenas comete crimes em níveis sociais que vão desde a nobreza até os redutos portuários, como também promove experiências sensoriais e estéticas ao seduzir e corromper homens e mulheres.

No caso de Gray, essa aptidão pela transgressão está diretamente associada à sua monstruosidade. Ao recusar parâmetros tradicionais, sejam aqueles de sexualidade ou de moralidade, o herói de Wilde leva suas experiências ao limite, sabendo tratar-se de um processo tanto formativo quanto autodestrutivo. $\mathrm{O}$ retrato que reproduz a crescente decadência de seu espírito figura como imagem monstruosa de uma interioridade que externamente se apresenta como jovem, civilizada e adorável. Nesse experimento de "teste" e "destruição" de limites, Dorian se torna um Mr. Hyde psicológico, enquanto seu rosto mantém um verniz de Dr. Jekyll, embora mais belo e sedutor. Sobre essa natureza transgressora de personagens considerados monstruosos, Jeha afirma:

Os limites sociais afetam nosso conhecimento do mundo e vice-versa. Toda vez que ampliamos nosso domínio epistemológico, quer conquistando novos territórios, quer desbravando-os, as fronteiras que controlam nossas vidas também se movem (embora nem de pronto, nem facilmente). o mesmo acontece quando descobrimos ou inventamos algo: nossa visão de mundo tem de acomodar outros seres ou novos fenômenos e isso pode causar incerteza epistemológica. Nossa experiência se baseia em fundamentos epistemológicos e ontológicos; mudanças epistemológicas vão gerar alterações ontológicas, e um acréscimo ontológico vai forçar nosso 
conhecimento a se expandir. Quando isso ocorre, sentimos que nossas expectativas de ordem - as fronteiras -, estabelecidas pela ciência, filosofia, moral ou estética, foram transgredidas. E transgressões geram monstros. $(2007$, p.21)

Nesse sentido, lemos Dorian Gray como um Monstro Moral, uma vez que suas escolhas e suas decisões caracterológicas estão perpassadas por pulsões que não apenas denegam a moralidade como objetificam outros seres, inocentes ou culpados, ou que passam justamente da inocência à culpa conforme travam contato com ele. O problema dessa busca incessante por cobaias é não apenas a tendência de seu pesquisador perder seu interesse por elas como também a rarearem com o tempo, uma vez que o vício por novas experiências exige um manancial rico de novos afetos, sensações e saberes. Por isso a busca nociva e destrutiva por renovadas transgressões que caracterizam o herói de Wilde até seu final metaforicamente suicida, no qual todos os limites foram testados, todos os gostos provados, todos os desejos saciados.

Na primeira temporada de Penny Dreadful, o Gray de Reeve Carney remetia a essa multiplicidade existencial e ao enfado de se ter feito praticamente tudo - pouco ou nada restando como combustível ao desejo. Quanto à sua bissexualidade, somada à caracterização andrógena do personagem, Logan o faz seduzir tanto Ethan Chandler quanto Vanessa Ives, além de utilizar a prostituta moribunda Brona para seus experimentos quando não para sua diversão. A cena em que Gray ordena o registro fotográfico de sua união sexual com Brona, no segundo episódio da primeira temporada, reúne poderosamente Eros e Tanathos não apenas pela violência do intercurso, como também pelo sangue tossido pela 
tuberculosa no rosto do amante. Figurando como uma espécie de vampiro psíquico, numa temporada cujo principal antagonista é um vampiro sanguinário, Dorian pula de experiência em experiência em busca de novas sensações e de novos parceiros. Logan resume sua visão sobre ele do seguinte modo:

It's a little bit like a sociopath... you start by pulling the wings off a fly, and that's interesting for a while, and then that gets boring. Maybe you kill a cat, and that's good for a while, but then that gets boring. Then what you do? This Dorian Gray has done all that. He's bored of it, he's languorous, he's done it all. (Apud GOSLING, 2015, p.109)

$\mathrm{Na}$ segunda temporada, esse esgotamento existencial porquanto libidinal - ou vice-versa - parece ter sido substituído por um único desejo não realizado: aquele relacionado a Vanessa Ives. É nesse interregno entre enfado erótico e desejo revivido que surge Angelique, uma prostituta transexual delicada e doce que oferece seus serviços a Dorian. Este rapidamente vê em tal personagem a possibilidade de um novo jogo amoroso/sexual no qual a não definição de gênero potencializa um novo conjunto de experiências a serem buscadas. Ora, o nome Angelique compreende em sua raiz uma alusão indireta não apenas à inocência angelical, como especialmente a uma androgenia que, não sendo nem um nem outro gênero, poderia potencializar todos. Além disso, a composição de palavras terminadas com o sufixo /-ique/ em francês - idioma do qual o nome provém - permite a atribuição de ambos os gêneros (nomes como Dominique e Véronique podem designar homens ou mulheres). Vemos nela outro tipo de monstro, diferente da monstruosidade moral 
de Dorian Gray. Trata-se de um Monstro Social que, não tendo espaço numa urbanidade não apenas binômica como moralista, é obrigada a criar alternativas - também transgressoras - para existir e conviver com outros seres.

O nome de tal amante de Dorian Gray retornará na abertura de outra cena entre os dois no quarto episódio, quando Angelique afirma "I don't admit to my real name, it's beneath contempt", chamando atenção para a decisão de deixar imerso em sombras caracteres pessoais que não lhe agradam, conclusão ecoada por Dorian Gray na cena seguinte, quando resume a relação entre os dois como "Knowing the secrets others don't". Antes do diálogo findar, com um beijo que escandalizará as famílias visitantes do Gossima Parlour onde os dois jovens sugestivamente jogam pinguepongue, Angelique afirma: "Being who we want to be... not who we are", expressão que resumirá muito de sua relação com Gray.

Esta frase se articula, num sutil movimento de ponto e contraponto, com as caracterizações de vários personagens de Penny Dreadful, que são muito mais protagonistas individualizados e construtores de seus próprios destinos do que coadjuvantes de qualquer ordem social preestabelecida. Vanessa e Chandler, por exemplo, são exemplos de párias sociais que resumiram suas vidas não a destinos pré-traçados, pela família no caso dele ou pela sociedade no caso dela. Com Angelique, essa formulação é mais significativa, pois é extensível não apenas a decisões profissionais ou afetivas, como também a questões associadas a identidade e gênero, numa readequação que também é da alteração corpórea. 
Mais adiante neste episódio, Dorian e Angelique vão ao teatro, sem haver a identificação de qual a peça que estaria em cartaz. A única coisa que testemunhamos é a surpresa de Angelique diante de um enredo dramático sobre um "brother and sister after all!", numa alusão a outro tabu: o incesto. A resposta de Dorian é reveladora: "So I finally found something that shocks you". Por mais que o rápido diálogo seja perpassado de descontração, fica implícito na cena que Gray está, mesmo que jocosamente, testando os limites dos parâmetros morais de sua acompanhante.

A continuação da cena investe na ilustração da marginalidade vivenciada por Angelique, quando um de seus antigos clientes, aparentemente um cavalheiro de nobreza e requinte, a acusa de têlo roubado. $O$ rápido encontro se encerra com o mesmo cavalheiro comentando aos seus companheiros: "little minx I told you about". "Minx" é um termo interessante, comumente associado ao gênero feminino e tendo por significado "mulher atrevida", "petulante", "vulgar" e/ou "disponível à prostituição". Angelique por sua vez não apenas aceita a humilhação acusatória, intensificada com a expressão "little freak", quanto impede Dorian de responder por sua "honra", como qualquer cavalheiro faria e como ele parece disposto a fazer.

Na doméstica cena seguinte, Angelique surge no saguão da casa de Dorian vestindo roupas masculinas "tomadas emprestadas" de seu amante. Quando questionada sobre o porquê de estar fazendo aquilo, o diálogo construído por Logan revela o fundo das opções não apenas sexuais como sociais de Angelique: "Being what I am?" é a resposta. Dorian diz que aquela versão masculinizada não é o que é ela de fato. A resposta de Angelique não apenas assume o 
termo usado pelo detrator no teatro, como também perscruta as intenções de Dorian no espaço da relação que estabelecem:

You prefer the freak. It adds spice for you, doesn't it? From the moment I was born, I was not as I was meant to be. No one spoke of it. My parents ignored me as best they could. So I came to London and created Angelique... leaving me fit for no trade but whoring... and myself fit for nothing but degradation and ridicule.

A segunda metade da fala revela de forma sumária as informações biográficas necessárias à condição de pária social de Angelique. Sendo quem era, não havia escolha a não ser assumir sua nova identidade num espaço de prostituição, único meio que aparentemente a aceitaria, apesar da "degradação e do ridículo". Dorian responde que também tem sido "diferente", recusandose ao exercício de alteridade que ela tenta construir na cena ao demonstrar que o vasto "conforto" dele em muito se diferencia de suas esparsas, quando não inexistentes, opções. O diálogo termina com Angelique perguntando se Gray a amará se decidir vestirse com roupas masculinas. A resposta de Dorian, "I care for who you are... not what you wear", novamente recupera o papel tão estranho a ele de "justiceiro social", em um exercício de empatia, antes negado, ao não se importar com as convenções.

O episódio seguinte tem por linha norteadora o baile dado por Dorian para "apresentar" Angelique à sociedade inglesa. Preocupada com as reações da mesma classe de pessoas que a humilharam na noite anterior, Angelique obtém de Dorian a seguinte resposta: "Anathema. In this house, we celebrate the unusual". O termo é tão específico que também merece atenção. "Anátema" 
é algo ou alguém que causa veemente desgosto, seja por algum aspecto físico, psicológico ou mesmo comportamental. Em outras palavras, é um monstro ou algo monstruoso. Neste sentido, as experimentações de Dorian levam Angelique aos seus limites, tanto físicos - como na cena de sexo que encerra o episódio anterior quanto psicológicos, quando não sociais. Para ele, fica dúbio se o baile para "introduzir Angelique" à alta sociedade é uma gentileza a ela ou um agrado próprio para engrandecer sua vaidade. Neste momento, Angelique está enlevada pelo rapaz, desejando levar roupas suas para a casa dele, ao passo que Gray já está à procura de outras experimentações, o que no baile apresenta-se como Lily, a misteriosa acompanhante de Victor Frankenstein.

No episódio final do arco Dorian/Angelique, intitulado "Memento mori", numa alusão às cenas mortuárias que desde o medievo relembram aos vivos da onipresença da morte, vemos o desfecho daquilo que Gray desejava, ou não, de sua trágica acompanhante. Deixando-a sozinha para buscar "uma nova aventura", Dorian mal pode prever que ela está prestes a descobrir seu segredo: o retrato amaldiçoado que registra os efeitos de seus crimes e experimentações; em outros termos, o retrato que registra em tela e tintas os traços e as cores da sua monstruosidade.

Antes de assassinar Angelique por haver descoberto seu segredo, Dorian se pergunta, ao contemplar seu retrato: "Don't we all want to paint ourselves into something... better than we are?". No que concerne a seu relacionamento com ela, é como se percebesse que seus esforços em aceitá-la, defendê-la e amála, não passassem de um esforço para "pintar a si próprio de um modo... melhor do que de fato ele era". Numa alusão interessante 
ao problema da representação na arte - da distância entre o objeto real de sua representação artística, problema estético com o qual o romance de Wilde já dialogava -, afasta-se da persona temporariamente criada para si, para Angelique e também para o espectador, e oferta uma conclusão mais condizente com o herói egoísta, amoral - quando não imoral - e homicida que nos ofertara a obra literária na qual figura como protagonista.

Penny Dreadful outra vez nos reapresenta os monstros clássicos recuperando não apenas sua "humanidade perdida" como também seu primitivismo terrível, tocando teclas que poderiam justamente fascinar/assustar sua audiência. Para recuperarmos a discussão inicial, interpretamos Dorian como Monstro Moral, uma vez que nele os crimes e a objetificação do outro não passam de estágios para uma busca identitária sua, pouco importando o bem-estar alheio. Sobre essa diferenciação, Jeha afirma:

Ao contrário de suas contrapartes física e metafísica, o mal moral parece estar claramente definido. Ele consiste na desordem da vontade humana, quando a volição se desvia da ordem moral livre e conscientemente. Vícios, pecados e crimes são exemplos de mal moral. Enquanto o mal físico é sempre sofrido, quer ele afete nossa mente ou nosso corpo, o mal moral surge quando, livre e conscientemente, infligimos sofrimento nos outros. Para que esse tipo de mal possa ocorrer, o agente tem de se decidir a abandonar sua integridade moral; assim, ele afeta tanto a vítima quanto o agente. (2007, p.16)

Por seu turno, Angelique corresponderia ao Monstro Social, sofredor não apenas física como psicologicamente por sua não 
adequação ao binômio comum. Nesse sentido, resulta como uma heroína repleta de pathos, sofrendo os reveses não apenas de sua marginalidade social como também os efeitos de um relacionamento destrutivo e utilitário, sorte de envolvimento que sua experiência prostibular já havia a apresentado. Dorian não é diferente de seus clientes pregressos, sendo talvez até pior, uma vez que, o que neles era objetificação sexual, no jovem imortal transmuta-se em perversão egotista, aceitando para si próprio que Angelique não passa de um experimento, de uma diversão momentânea, de uma sensação que, após conhecida, pode então ser descartada.

Vale ainda atentar que tanto Angelique quanto Dorian compartilham com Vanessa Ives uma característica moderna do monstro: a beleza, outro favor que os humaniza, de maneira a criar um novo paradigma da monstruosidade, como explica David Roas:

Ello explica que en muchos casos ya no se juegue obsesivamente con el aspecto físico del monstruo (a diferencia de las encarnaciones clásicas, que exacerbaron la deformidad y fealdad de estos seres), lo que impide reconocerlos por su exterior, sino que se potencie - por medios diversos la problematización de su rasgo esencial: la imposibilidad (y lo que ello implica para el receptor). (2014, p.114)

Neste caso, a trajetória de Angelique é o percurso comum do pária social, do monstro real, que, não tendo espaço ou mesmo oportunidade para qualquer outra função real numa sociedade de papéis preordenados, subjuga-se à opressão do outro e à destruição de si mesma, ou em suas próprias palavras, à "degradação e ao ridículo". De acordo com Gil, podemos 
interpretar seu percurso como um caminho em direção a uma humanização interrompida, quer pela opressão social, quer pela destruição física nascida de uma relação atrativamente afetiva em seu início e abusiva no seu desenrolar.

Esta figuração popular da monstruosidade remetenos para todo um conjunto de rituais sociais e de técnicas que visam tornar o desejo socialmente integrado. Uma vez esses rituais cumpridos, a monstruosidade desaparece e o homem volta a tornar-se humano. 0 que significa que nesses contextos culturais o signo do humano é dado pela capacidade de reproduzir a vida da comunidade: é homem aquele que sabe seguir as regras sociais que asseguram a sobrevivência individual e colectiva. Ser humano, reconhecer-se tal, é submeter-se à iniciação da cultura e identificar-se como um ser dessa mesma cultura. Assim, a aquisição de uma autêntica alma - para que desapareça a do animal que habita o corpo monstruoso - faz-se através de uma série de etapas que visam um certo domínio do corpo. Trata-se de o preparar para receber 0 seu próprio duplo. (2006, p.90-91, grifo nosso)

Neste sentido, por bem ou por mal, Angelique está mais próxima dessa humanização perversa, na qual se subjugar ao poder do outro, às palavras do outro, aos valores do outro, diminui em si sua "monstruosidade". Todavia, trata-se de uma falsa humanização, uma vez que se humanizar diante do outro é prostituir a si própria, papel ironicamente interpretado por ela, prostituta e consorte. Quando ela aceita as acusações do antigo cliente no teatro, ou evidencia preocupação diante das opiniões da sociedade ou mesmo diante das opiniões de Dorian, é como se tentasse calar essa marca de diferenciação que é somente sua. Marca que Gray, por exemplo, 
não tem problema algum em aceitar e manter. Pelo contrário, parece-nos que sua "Marca de Caim" é almejada e abraçada, pois o diferencia do comum social. Se ele vive na casa em que o "incomum é celebrado", o próprio Dorian é um Anátema, palavra usada por ele para definir - ou definir-se - uma existência na qual o amaldiçoado, o condenado, o execrado pela sociedade moralista torna-se o ideário a ser buscado.

Seguidor de um evangelho invertido, Dorian reúne não apenas os construtos sociais comumente associados ao patriarcado opressor como também a desconstrução desse ideário, por mais que, no caso de sua relação com Angelique, o resultado seja a tradicional assimetria. Sobre esta, há na relação entre as duas personagens a possibilidade de pensarmos nas diferenças de gênero, marcadas social e culturalmente. Angelique precisa não apenas de uma validação social por parte de seu companheiro, como também aceita as nomenclaturas que lhe foram destinadas, todas elas preconceituosas, grosseiras e ofensivas, surgindo passiva e estranhamente submissa às ofensas simplistas recebidas. Vivendo nas zonas limítrofes do gênero - enquanto Dorian apenas flerta com elas - Angelique está no não lugar do gênero e do desejo, subjugada a uma visão não apenas depreciativa do trans como também do feminino, que alerta a importância de tais discussões.

\section{CONSIDERAÇÕES FINAIS}

Apesar de Penny Dreadful se passar no século XIX e de reconstruir a época retratada, o olhar direcionado aos protagonistas é bastante contemporâneo, problematizando a monstruosidade de cada um, sem, no entanto, torná-los mártires 
ou heróis injustiçados, como tão comumente acontece. O horror parece antes advir de comportamentos inesperados dos (anti) heróis (podemos pensar no assassinato de Angelique por Dorian, por exemplo), do que dos monstros coadjuvantes e típicos que permeiam a série, relegados a um papel bastante secundário (a saber, vampiros e necromantes). Logo, a simpatia e empatia do espectador são regularmente postas em cheque. Se Gray parecia um justiceiro social no começo da segunda temporada, salvando Angelique da humilhação pública, transforma-se em assassino frio quando seus interesses pessoais são ameaçados. Torna-se um monstro moral em oposição a Angelique, vista pela preconceituosa sociedade de seu tempo como um monstro social, e julgada, assim, como o fora a Criatura de Frankenstein, por sua diferença físico-genérica - na altura ainda rara. No entanto, ao contrário da Criatura shelleyana - que, renegada, torna-se cruel e vingativa, seguindo o pensamento rousseauniano de que a sociedade nos corrompe -, Angelique permanece íntegra, sem se deixar macular pela maldade humana.

John Clare, por sua vez, é capaz de se emocionar com poesia e caridade, o que denota sua capacidade de compaixão, apesar de ter assassinado brutalmente Proteus e Van Helsing, como forma de vingança e provocação a Victor. Ou seja, sua empatia parece ser direcionada ou, no mínimo, cambiante. Por sua vez, Vanessa Ives, na sua qualidade de "mulher moderna" e bruxa, redime-se para si (posto que seja a maior - senão única - vítima de suas aflições) por meio da caridade e, por consequência, de sua amizade com John Clare, por quem nutre grande admiração. Ambos conseguem demonstrar enorme capacidade empática 
humanista, a despeito do nascimento profano de um e das habilidades heréticas da outra.

Em suma, neste processo de humanização, a Bruxa e o Monstro Biológico se humanizam pela caridade e pela poesia que Ihes permite ver a beleza das pequenas coisas; Dorian pela aparente empatia (quando a sente), enquanto Angelique se torna naturalmente humanizada (sempre em uma perspectiva do espectador, como é evidente) devido às mudanças de paradigmas contemporâneos, que, ao saírem da dicotomia estritamente fisiológica, passaram a incluir em seu leque de possibilidades genéricas novas formas de identificação matizadas e relativizadas.

Todas essas interessantes oscilações enquanto personagens flertam com a ideia do deslocamento do conceito de "monstro" na contemporaneidade. Sua ambiguidade está ligada às transgressões do padrão socialmente aceito da época retratada e à condição de outsiders ou freaks sociais. Todos eles escapam do que é considerado moralmente adequado para tentarem se encontrar e se entender, para não dizer se "encaixar" naquela sociedade e sobreviver. Isso explica "o intenso fascínio actual pela monstruosidade. Os monstros são-lhe absolutamente necessários para continuar a crer-se homem" (GIL, 2006, p.14). Por isso a atualidade de uma série como Penny Dreadful. Afinal, "o monstro não se situa fora do domínio humano: encontra-se no seu limite" (2006, p.14). 


\section{REFERÊNCIAS}

FONDANÈCHE, Daniel (2006). 'L'Uchronie comme moteur de I'Histoire (im) possible: L'Appel du 17 juin d'André Costa". Cycnos, 22(2), 1-9. In http://revel. unice.fr/cycnos/index.html?id=603 Acesso em 26.Jul.2015.

GIL, José (2006). Monstros. Lisboa: Relógio D’Água.

GOSLING, Sharon (2015). The Art and Making of Penny Dreadful. Londres: Titan Books.

JEHA, Júlio (Org.) (2007). Monstros e Monstruosidades na Literatura. Belo Horizonte: UFMG.

LLOBERA, Patricia (2015). "Todos los monstruos son humanos: el imaginario cultural y la creación de bestiarios contemporáneos en American Horror Story". Brumal-Revista de Investigación sobre lo Fantástico, 3(2), 69-88. In http://revistes. uab.cat/brumal/article/view/V3-n2-Ilobera/pdf_10. Acesso em 06.Jan.2016.

LOVECRAFT, Howard (2007). O Horror Sobrenatural em Literatura. Tradução de Celso M. Paciornik. São Paulo: lluminuras.

ROAS, David (2008). "Lo fantástico como desestabilización de lo real: elementos para una definición". In: PELLISA, Teresa; SERRANO, Fernando (Orgs.). Ensayos sobre ciencia ficción y literatura fantástica. Madri: Universidad Carlos III. p.94-120.

. (2012). "Mutaciones posmodernas: del vampiro depredador a la naturalización del monstruo". Letras \& Letras, Uberlândia, 28(2), 441-455. In http:// www.seer.ufu.br/index.php/letraseletras/issue/view/1096. Acesso em 09.Jan.2016. . (2014). "El monstruo posmoderno y los límites de lo fantástico". In: GARCÍA, Flavio; BATALHA, Maria Cristina; MICHELLI, Regina (Orgs.). (Re)Visões do Fantástico: do centro às margens; caminhos cruzados. Rio de Janeiro: Dialogarts. p.107-120.

SHELLEY, Mary (2013). Frankenstein. Tradução de Bruno Gambarotto. São Paulo: Hedra.

\section{REFERÊNCIA TELEVISIVA}

LOGAN, John (2014). Penny Dreadful. Produção de Desert Wolf Productions e Neal Street Productions, criação de John Logan. Estados Unidos: Showtime. 